\title{
Design of computerized monitoring and processing system for magnetic field controlling against the phenomenon of black powder in crude oil pipelines
}

\author{
Hussain Attia ${ }^{1}$, Saad Balhassan ${ }^{2}$ \\ ${ }^{1}$ Electrical, Electronics and Communication Engineering Department, \\ American University of Ras Al Khaimah, United Arab Emirates \\ ${ }^{2}$ Chemical and Petroleum Engineering Department, American University of Ras Al Khaimah, United Arab Emirates
}

\begin{tabular}{l}
\hline \hline Article Info \\
\hline Article history: \\
Received Sep 30, 2019 \\
Revised Mar 21, 2020 \\
Accepted Mar 31, 2020 \\
\hline
\end{tabular}

\section{Keywords:}

Alternative solution

Black powder

Computer system

Controlled magnetic field

Conventional removal methods

Resistivity sensor

\begin{abstract}
Black power represents the main difficulty faced by the oil flow in pipelines. The negative effect of this powder reaches to stop the oil flow due to clogging the pipelines, in addition to the damaging of the crude oil pumps. Many solutions have been proposed in literature based on chemical or physical processes. On the other side, applying the fixed magnetic field has been presented in separation and extraction process of metal impurities in water pipelines applications. From these facts, this paper proposes an alternative solution (idea, design, and methodology for future implementation) for the black power removing from oil pipelines. The proposed system works on firstly sensing the resistivity parameter in the crude oil as an indication about the oil status with respect to the quantity of the black powder particles, then works on monitoring and controlling the level, location, and polarity of the required magnetic field that to work on cracking particles cracking function that in order to facilitate the crude oil motion in the pipelines. In addition, the proposed solution presents a new design of electrical resistivity sensor as an important indication in terms of evaluating the proposed system performance.
\end{abstract}

Copyright () 2020 Institute of Advanced Engineering and Science. All rights reserved.

\section{Corresponding Author:}

Hussain Attia,

Electrical, Electronics and Communication Engineering Department,

American University of Ras Al Khaimah,

Ras Al Khaimah, 10021, United Arab Emirates.

Email: hattia@aurak.ac.ae

\section{INTRODUCTION}

The oil flow in pipelines has the problem of including the mixture of fine particles of different metals and non-metals which is known as black powder. Most pipeline operators are familiar with this problem and with its consequences in all oil treatment stages starting from first step of well's pumps till the last step of oil delivery [1-3]. Wet substances, dry substances, and fine powder are all representing different forms of black powder. Any form of this powder can either decelerating the oil rate or reducing the product's quality. As well as that there are many environmental hazards on human and animal health due to the black powder's components like mercury, radioactive and pyrophoric materials like iron sulfides. By removing or reducing the black powder, definitely, the consequences of the environmental hazards will reduce, in addition to an enhancement in terms of overall oil system performance and quality of the produced oil $[4,5]$. The study in [6] showed and confirmed that the black powder has an amorphous nature, in different particle sizes and concluded that the black powder's particles can break and shear into submicron sizes easily as shown in Figure 1. 
Black Powder removal has been done using conventional methods of a chemical or a physical process, these processes are suffering from many demerits of high cost and time delay, such as most the highly cost of chemical cleaning process, an addition to the cost of pipelines drying process [7, 8]. Whereas the black powder removal by a physical process needs to extra power for the pigging and the high velocity flushing process, and pigging with solvents or gel, using cleaning tools for pipelines as shown in Figure 2 (a), whereas the cleaning process tools shown in Figure 2 (b) $[4,6,9]$.

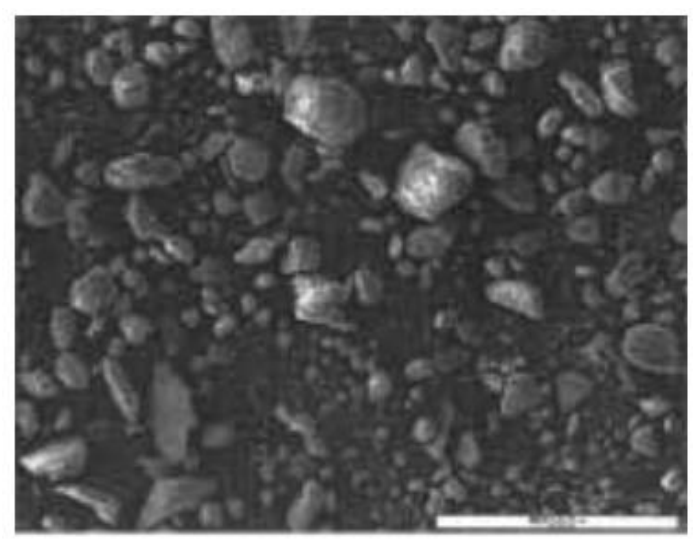

Figure 1. Black powder particles through an electron microscope [6]

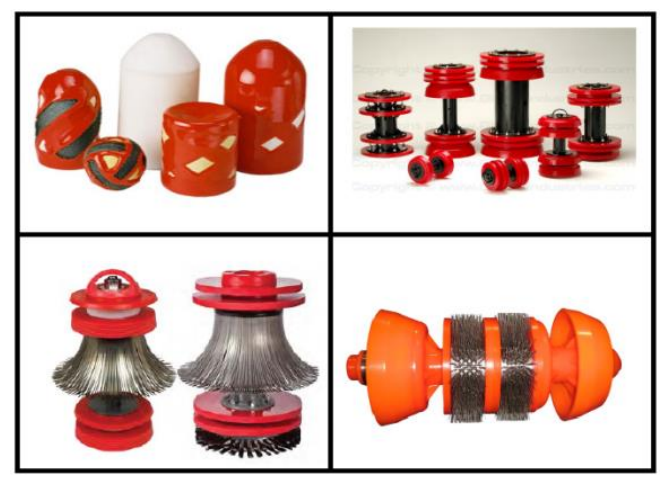

(a)

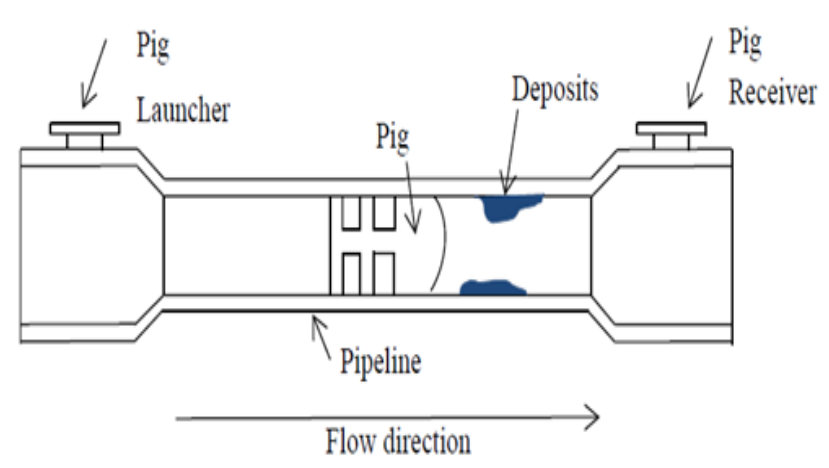

(b)

Figure 2. Various mechanical cleaning pigs, (a) different shapes of cleaning tools, (b) cleaning process [4]

\section{APPLYING MAGNATIC FIELD IN SEPARATION PROCESS}

Adopting the magnetic field as au effective solution for the process of separating the mineral ores as impurities from the mixtures is proposed since a long time [10]. Magnetic impurities removal process have been experimentally investigated on a diluted suspension in the study of [11], in which theoretical models have been described satisfactorily for magnetic separating process. In spite of Svoboda in [11] was presented the High-Gradient Magnet in 1986 as an effectiveness solution for separating process in mining industry, the study needed to combine between the related theory and industrial sides.

Due to the magnetic nature of iron species, conventional methods of chemical process did not effective for magnetic impurities removal compared to the magnetic field and the effectiveness of the field in removing process [10], the study of [10] has been concluded and confirmed that the technology of the high gradient magnetic separation (HGMS) is feasible for magnetic impurities separating process, in addition to the possibility of using permanent magnet for the same aim. The study of [12] has been focused on the performance of a high-gradient magnetic separator in terms of ultrafine particles based on the pulsating technique through HGMS system, it has been confirmed that the performance considered of a low cost process due to the lower energizing cost. Whereas High gradient magnetic separator's performance analysis has been presented in [13] for powder material processing. Other studies of [14-18] are also shown the impact of the black powder removal from Oil Pipelines of the oil production, and fluid properties. 
From the above studies of [10-18], it is clearly noticeable that the effectiveness of magnetic field for the extracting the metals' impurities from the mixtures, here the important conclusion is that there will be high positively effect from using magnetic field in cracking the black powder particles in the crude oil.

\section{PROPOSED IDEA AND SYSTEM DESIGN}

Based on the above about the function of the magnetic field, and comparing to the conventional methods of black powder removal, and also based on the abilities of computerized systems for monitoring and/or controlling functions [19-32], the presented method in this paper focuses on controlling the level, location, and polarity of the allocated magnetic field in order to remove the black powder from crude oil. On the other hand, due to adopting the electrical resistivity measuring for well logging development [33], a new design of resistivity sensor in presented in this study in order to sense the crude oil resistivity will be presented through which the proposed system's performance can be evaluated. The proposed sensor works on measuring the oil resistivity before and after the considered activity of black powder removal. The oil resistivity is adopted to evaluate the positive effect of the magnetic field on cracking the black powder particles, in other words, the crude oil resistivity will be increased after the particles cracking action due to the increase of crude oil penetration among the black powder particles. The controlling function to magnetic field strength based on the fact of that Passing direct current through an inductor results a vector quantity of magnetic field of unit tesla [T], the magnetic field strength is proportional with the level of passing current I and number of conductor turns $\mathrm{N}$ whereas inversely proportional with the length of the core $\mathrm{L}$, and adding the iron core will significantly increase the magnetic field strength as shown in Figure 3 and explained in (1), and (2) in which $\mu_{\mathrm{o}}$ is constant and represents the air permeability [34, 35].

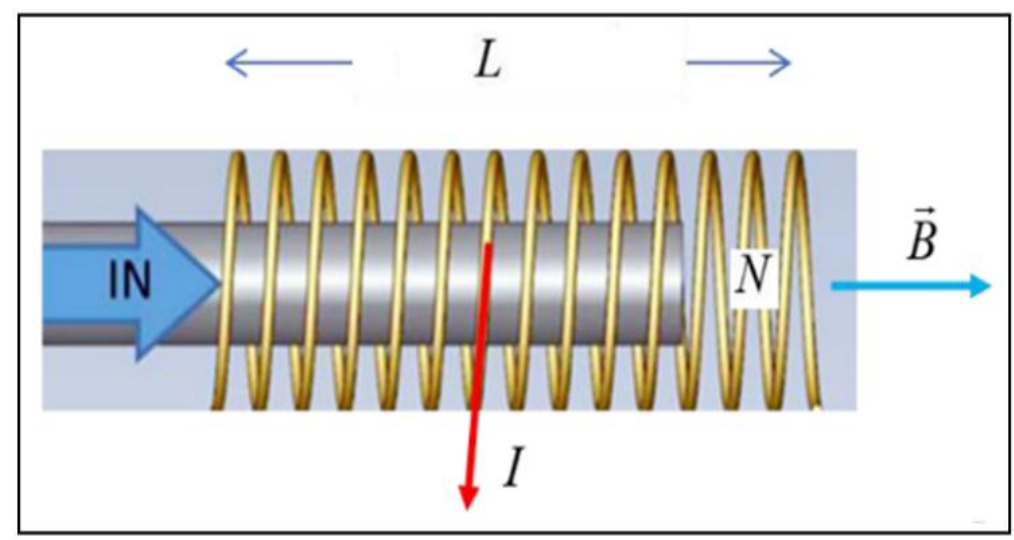

Figure 3. The magnetic field direction in a solenoid [29]

$$
\begin{aligned}
& B_{\text {air }}=\frac{\mu_{o} N I}{L} \\
& B_{F e}=\frac{\mu_{r} \mu_{o} N I}{L}=\mu_{r} B_{\text {air }}
\end{aligned}
$$

The proposed design of the black powder removal system adopts the flexibility of the modification of any relevant parameter such as the power consumption of the induced magnet and the size or shape of the resistivity sensor, in addition to the flexibility in terms of controlling and monitoring functions through a computerized processor. Figure 4 shows a block diagram of the proposed system, the system includes two sensing units, each of them involves, resistivity sensor and adaptation circuit. The function of each sensing unit is producing an analog voltage with voltage range proportional with the crude oil passing through the sensor location. The two sensing units are located before and after the designed magnets that to accurately evaluate the effectiveness of the magnets' performance. The level of power which will be consumed for producing induced magnets that can be monitored and controlled through a computerized system. The proposed system involves a variable DC power supply which can be represented by high power direct current DC drive which is able to control the delivered load voltage and current. 


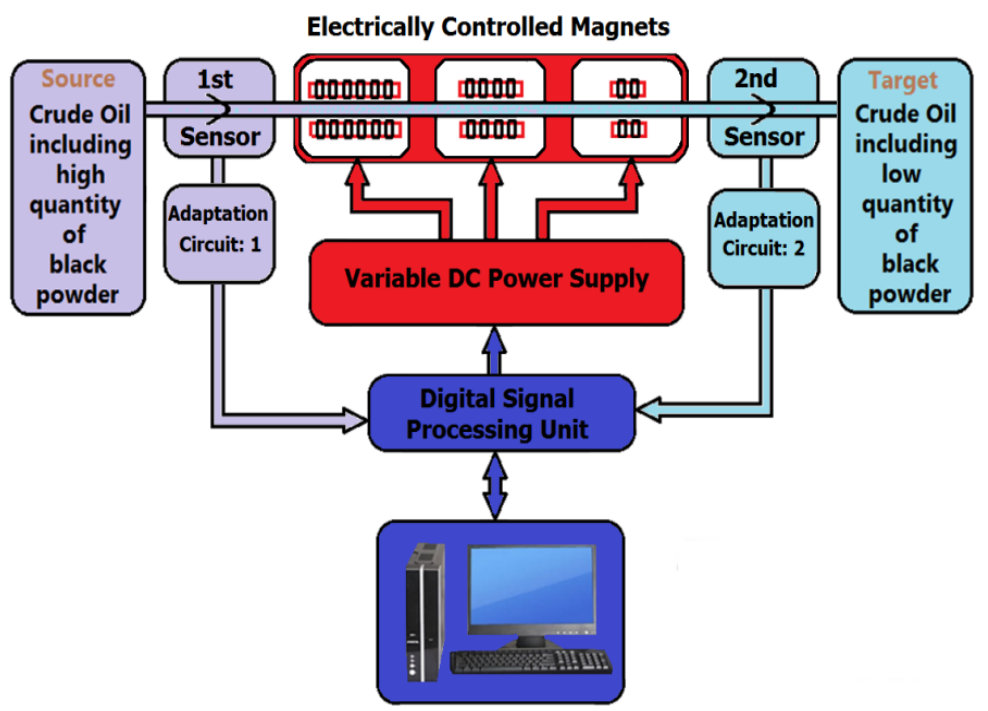

Figure 4. Block diagram of the proposed magnetic system for black powder removal application

\section{RESISTIVITY SENSOR DESIGN}

The idea of the proposed sensor of resistivity measurement is proposed based on the relationship of the resistance value based on material resistivity (3) [36], then the resistivity value can be calculated by (4)

$$
\begin{aligned}
& \mathrm{R}=\frac{\rho l}{A} \\
& \rho=\frac{R A}{l}
\end{aligned}
$$

On the other side the practical value of sample resistance can be found by measuring the value of voltage across the material sample and the passing current through the sample, then applying Ohm's law as shown in (5).

$$
\mathrm{R}=\frac{V_{R}}{I_{R}}
$$

So for any value of length $l$ and area $A$, the resistivity value can be determined using (4). Figure 4 shows two shapes of the proposed sensor. Here it is clear to notice that the area $A$ of Figure 4 (a) can be determined using (6) whereas the area $A$ of Figure 5 (b) can be determined using (7).

$$
\begin{aligned}
& A=X \times Y \\
& A=\pi \times r^{2}
\end{aligned}
$$

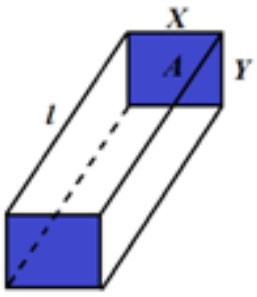

(a)

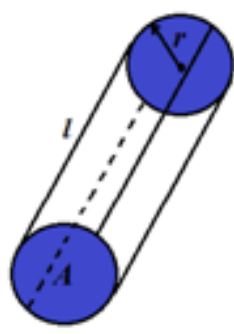

(b)

Figure 5. Shapes of the proposed sensor for resistivity measurement 


\section{CONCLUSION}

An alternative solution for black powder removal purpose is presented in this paper. Based on an accurate study to the literature of the mentioned purpose field, this study found that the induced magnet can play an effective role in this regard. A new system design with new methodology has been presented in this study through a computerized system. The system design is characterized flexibility, scalability and integration because it works on firstly sensing the samples, monitoring and analysis the sensing parameters then controlling the load power which represents the strength of the induced magnet. Also the presented solution introduces a new sensor design in order to measure the instantaneous value of the crude oil resistivity at the location of testing. The presented design is promising prototype a successful prototype of future implementation.

\section{ACKNOWLEDGEMENTS}

The authors appreciate the financial support provided by school of engineering, American University of Ras Al Khaimah - UAE, www.aurak.ac.ae/en/school-of-engineering/.

\section{REFERENCES}

[1] J. Smart and R. Winters, "Black powder migration in gas pipeline and associated problems," The pipeline pigging and integrity management conference, Feb. 2008.

[2] O. Olabisi, S. Al-Sulaiman, A. Jarragh, Y. Khuraibut, and A. Mathew, "Black powder in export gas lines," Materials Performance, pp. 50-54, 2017.

[3] M. Hedayati-dezfooli, "Prediction of particle laden flow in gas pipe," M.Sc. thesis, Ryerson University, 2009.

[4] T. Crosby, D. Joe, A. Prefontaine and H. Tsaprailis, "Cleaning of pipelines for abandonment, final report," Petroleum Technology Alliance of Canada, Sep. 2015.

[5] John Smart, "Keep on Moving-Talks about calculating velocity for solid particle movement in oil and gas pipelines," World Pipelines, Dec. 2009.

[6] Nikolaos A. Tsochatzidis, and Konstantinos E. Maroulis, "Methods help remove black powder from gas pipelines," Oil \& Gas Journal, vol. 105, no. 10, Mar. 2007.

[7] M. A. Mahmoud, M. S. Kamal, B. S. Ba Geri, and I. A. Hussein, "Removal of pyrite and different types of iron sulfide scales in oil and gas wells without H2S generation," International Petroleum Technology Conference, Dec. 2015.

[8] D. F. Aloko and A. D. Mohammed, "Biocide injection as a mean of internal corrosion control of oil pipelines," Indian Journal of Chemical Technology, vol. 14, pp. 536-538, Sep. 2007.

[9] O. Trifilieff, and T. H. Wines, "Black powder removal from transmission pipelines: Diagnostics and solutions," Pall Fuels and Chemicals, pp. 1-12, Mar. 2009.

[10] Giacomo Mariani, "Theoretical and experimental study of the magnetic separation of pollutants from wastewater," Ph.D, Thesis in Electrotechnical Engineering Alma Mater Studiorum, University of Bologna, 2009.

[11] J. Svoboda, "Applicati on of high-gradient magnetic separation," Physical Separation in Science and Engineering, vol. 2, no. 2, pp. 51-68, 1986.

[12] Luzheng Chen, Zhihua Qian, Shuming Wen, and Songwei Huang, "High-gradient magnetic separation of ultrafine particles with rod matrix," Mineral Processing and Extractive Metall. Rev., vol. 34, no. 5, pp. 340-347, 2013.

[13] Alicja Idziaszek-Gonzalez, Waldemar Kozlowski, "High gradient magnetic separation for powder material processing," Electric Power Engineering \& Control Systems, Nov. 2013.

[14] Saad Balhasan, Mohamed Omar, Hassan Alhamoudi, Abdulrahman Alzaabi, Salma Abdelwahab, "Black powder removal from oil pipelines," SPE-198105-MS, SPE Kuwait Oil \& Gas Show and Conference, Oct. 2019.

[15] Saad Balhasan, Daniel A. Michael, "Case Study on determining the critical production rate for bottom water coning in the majed (EE-Pool) reservoir," Journal of Engineering and Applied Sciences, vol. 15, no. 4, pp. 925-931, 2020.

[16] S. RahmatAllah, S. Balhasan, K. Hossin, F. Al Ali, "A review of water shutoff treatment methods in oil fields," Presented At The International Conference On Energy, Water \& Environmental Science, Nov. 2018

[17] Saad Balhasan, Bader Al Kandari, Mohamed Omar, Jassim Al-Otaibi, Hamad Al-Shakhis, Ali Al Amer, "Development of an empirical equation to predict the performance of CO2-WAG Flooding," SPE Kuwait Oil \& Gas Show and Conference. Society of Petroleum Engineers, Oct. 2017.

[18] Saad Balhasan, Mohammad Jumaa, Ahmed Elbagir, "Development of a correlation to predict water-flooding performance of sandstone reservoirs based on reservoir fluid properties," International Journal of Applied Engineering Research, vol. 12, no. 10, pp. 2586-2597, Jun. 2017

[19] HA Attia, TKS Freddy, HS Che, WP Hew, AH El Khateb, "Confined band variable switching frequency pulse width modulation (CB-VSF PWM) for a Single-Phase inverter with an LCL filter," IEEE Transactions on Power Electronics, vol. 32, no. 11, pp. 8593-8605, 2017.

[20] B. Jyothi, M. Venugopala Rao, "Carrier-based pwm technique for inverter-fed multiphase induction motor," International Journal of Electrical and Computer Engineering (IJECE), vol. 6, no. 5, pp. 1967-1984, Oct. 2016.

[21] Hussain A. Attia and Fernando delAma Gonzalo, "Stand-alone PV system with MPPT function based on fuzzy Logic control for remote building applications," International Journal of Power Electronics and Drive System (IJPEDS), vol. 10, no. 2, pp. 842-851, Jun. 2019. 
[22] Hussain Attia, "Evaluation of selective harmonic elimination pulse width modulation technique for unipolar SinglePhase H-Bridge inverter: Comparative study," International Journal of Power Electronics and Drive Systems (IJPEDS), vol. 9, no. 3, pp. 1157-1165, 2018.

[23] Hussain Attia, "Fuzzy logic controller effectiveness evaluation through comparative memberships for photovoltaic maximum power point tracking function," International Journal of Power Electronics and Drive Systems (IJPEDS), vol. 9, no. 3, pp. 1147-1156, 2018.

[24] Afarulrazi Abu Bakar, Wahyu Mulyo Utomo, T. Taufik, Asmarashid Ponniran, "Modeling of FPGA- and DSPbased pulse width modulation for Multi-Input interleaved DC/DC Converter," International Review of Electrical Engineering (I.R.E.E.), vol. 14, no. 1, pp. 79-85, 2019.

[25] Mahdi Tousizadeh, Hang Seng Che, Jeyraj Selvaraj, Nasrudin Abd Rahim, Boon-Teck Ooi, "Fault-tolerant fieldoriented control of three-phase induction motor based on unified feedforward method," IEEE Transactions on Power Electronics, vol. 34, no. 8, pp. 7172-7183, 2018.

[26] Baten Md Shihab, Mahdi Tousizadeh, Hang Seng Che, "Continuous and discontinuous PWM methods for symmetrical six-phase induction motor with single isolated neutral," Arabian Journal for Science and Engineering, vol. 45, pp. 1885-1895, 2020. [Online], Available: https://doi.org/10.1007/s13369-019-04267-x.

[27] Tan Kheng Suan Freddy, Nasrudin A Rahim, Wooi-Ping Hew, Hang Seng Che, "Comparison and Analysis of Single-Phase Transformerless Grid-Connected PV Inverters," IEEE Transactions On Power Electronics, vol. 29, no. 10, pp. 5358-5369, Oct. 2014.

[28] S. Nagaraja Rao, D. V. Ashok Kumar, and Ch. SaiBabu, "Grid connected distributed generation systemwith high voltage gain cascaded DC-DC converter fed asymmetric multilevel inverter topology," International Journal of Electrical and Computer Engineering (IJECE), vol. 8, no. 6, pp. 4047-4059, Dec. 2018.

[29] Nyayu Latifah Husni, Siti Nurmaini, Irsyadi Yani, and Ade Silvia, "Intelligent sensing using metal oxide semiconductor based-on support vector machine for odor classification," International Journal of Electrical and Computer Engineering (IJECE), vol. 8, no. 6, pp. 4133-4147, Dec. 2018.

[30] Kwang T. C., Mohd Luqman Mohd Jamil, Auzani Jidin, "Torque improvement of PM motor with semi-cycle stator design using 2D-finite element analysis," International Journal of Electrical and Computer Engineering (IJECE), vol. 9, no. 6, pp. 5060-5067, Dec. 2019.

[31] S. Vijaya Madhavi, and G. Tulasi Ram Das, "Variable structure control for an isolated boost converter used in fuel cell applications," International Journal of Electrical and Computer Engineering (IJECE), vol. 9, no. 6, pp. 4493-4506, 2019.

[32] Jayasri B. S., and G. R. Rao, "Analytical modelling of power efficient reliable operation of data fusion in wireless sensor network," International Journal of Electrical and Computer Engineering (IJECE), vol. 8, no. 6, pp. 4637-4645, 2018.

[33] Jürgen S., "Basic well logging and formation evaluation," Bookboon 1st Edition, The Ebook Company, pp. 44-66, 2015. [Online], Avaliable: https://home.czu.cz/storage/52485_basic-well-logging-and-formation-evaluation.pdf.

[34] "Electromagnetism Magnetic Fields Magnetic Flux," Vusual Physics Online, [Online], Available: http://www.physics.usyd.edu.au/teach_res/hsp/sp/mod6/m6Flux.pdf.

[35] Juan C. Olivares-Galván, Iván Hernández, Pavlos S. Georgilakis, Eduardo Campero-Littlewood, "Calculation of the magnetic field intensity in a rectangular conductor carrying current in electromagnetism introductory courses," Proceedings of the COMSOL Conference Boston, 2009.

[36] Heaney, Michael B., "Electrical conductivity and resistivity," Electrical Measurement, Signal Processing, and Displays. Ed. John G. Webster. CRC Press, 2003.

\section{BIOGRAPHIES OF AUTHORS}
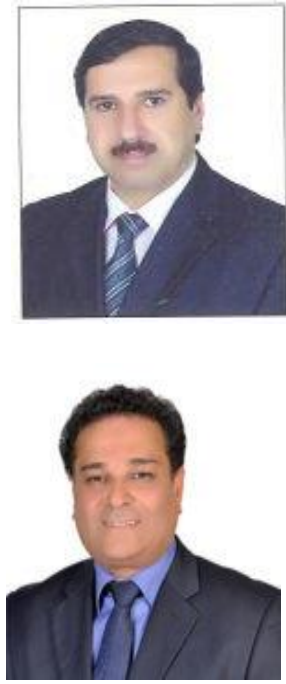

Dr. Hussain Attia earned his Ph.D. degree in Power Electronics from University of Malaya, Kuala Lumpur, Malaysia, and M.Sc. degree in Electronic Engineering from the University of Technology, Baghdad, Iraq. Hussain's research interests include power electronics system design and implementation, AC \& DC Drives, PWM Inverters (single phase \& three phases), harmonics elimination and reduction techniques, Maximum Power Point Tracking algorithms, and intelligent control.

Dr. Saad Balhasan gained his ph.D. degree in Petroleum Engineering from the University of Wyoming, USA, and his MS in Reservoir Geoscience and Engineering from IFP School, France, MS in Petroleum Economics and Management from IFP School, France, ME in Petroleum Engineering from Colorado School of Mines. Saad's research interest are reservoir engineering, heavy oil, CO2-EOR, reservoir management and economic evaluation, and design and Evaluation of Oil Contracts. 